\title{
Updates to the Appropriate-Use Criteria for Somatostatin Receptor PET
}

\author{
Thomas A. Hope \\ University of California, San Francisco, San Francisco, California
}

$\mathbf{T}$ he guidelines of the Centers for Medicare and Medicaid Services require that appropriate-use criteria (AUC) be reviewed yearly. The somatostatin receptor (SSTR) PET AUC was originally approved in 2017 (1). There were no significant updates in the first 2 annual reviews, but this year there are 3 important updates (2) (please see the supplemental materials, available at at http://jnm.snmjournals.org).

The first update is the addition of ${ }^{64} \mathrm{Cu}$-DOTATATE as an accepted SSTR-PET radiotracer. With the recent Food and Drug Administration approval of this radiotracer, the AUC committee consensus was it should be considered equivalent to ${ }^{68} \mathrm{Ga}-$ DOTATATE and ${ }^{68} \mathrm{Ga}$-DOTATOC for patients with neuroendocrine tumors. Existing data demonstrate that ${ }^{64} \mathrm{Cu}$-DOTATATE functions at least similarly to existing SSTR-PET radiotracers $(3,4)$.

The second update is the inclusion of a new indication: restaging of patients after completion of PRRT (score 7-appropriate). All AUC documents grade indications on a scale from 1 to 9 . Scores of 7-9 indicate that the use of the procedure is appropriate for the specific scenario and is generally considered acceptable. Given the absence of response seen on conventional imaging (CT and MRI), SSTR-PET can help provide a new baseline for disease that appears stable on conventional imaging but may show a response on SSTR-PET. Changes in SUVs alone do not necessarily indicate response or progression; response should be assessed by the disappearance of known lesions or the development of new lesions on SSTR-PET. This information can be important in order to aid in interpretation of subsequent SSTR-PET studies where disease may appear unchanged in comparison to pretreatment SSTR-PET, but has worsened compared to a posttreatment SSTR-PET. Therefore, SSTR-PET can be used 9-12 mo after completion of PRRT to obtain new baseline imaging data for future comparison.
Lastly, the updated AUC attempts to address the issue of the number of SSTR-PET studies that can be performed on patients with neuroendocrine tumors. SSTR-PET may play an important role in disease evaluation or treatment planning at various times during a patient's disease course. Because patients with neuroendocrine tumors frequently live with their disease for well over a decade, any limitation on the number of SSTR-PET studies over a patient's lifetime is not warranted.

\section{DISCLOSURE}

Thomas Hope is an advisor for Ipsen and a consultant for Curium and receives research grant support from Advanced Accelerator Applications. No other potential conflict of interest relevant to this article was reported.

\section{REFERENCES}

1. Hope TA, Bergsland EK, Bozkurt MF, et al. Appropriate use criteria for somatostatin receptor PET imaging in neuroendocrine tumors. J Nucl Med. 2018;59: 66-74.

2. Appropriate use criteria for somatostatin receptor PET imaging in neuroendocrine tumors. SNMMI website. http://www.snmmi.org/ClinicalPractice/content.aspx? ItemNumber $=23260$. Approved September 9, 2017. Updated September 2019. Accessed October 6, 2020.

3. Pfeifer A, Knigge U, Binderup T, et al. ${ }^{64} \mathrm{Cu}$-DOTATATE PET for neuroendocrine tumors: a prospective head-to-head comparison with ${ }^{111}$ In-DTPA-octreotide in 112 patients. J Nucl Med. 2015;56:847-854.

4. Delpassand ES, Ranganathan D, Wagh N, et al. ${ }^{64} \mathrm{Cu}$-DOTATATE PET/CT for imaging patients with known or suspected somatostatin receptor-positive neuroendocrine tumors: results of the first U.S. prospective, reader-masked clinical trial. J Nucl Med. 2020;61:890-896.
Received Sep. 29, 2020; accepted Sep. 29, 2020.

For correspondence or reprints contact: Thomas A. Hope, University of California, San Francisco, 505 Parnassus Ave., San Francisco, CA 94143. E-mail: thomas.hope@ucsf.edu COPYRIGHT (c) 2020 by the Society of Nuclear Medicine and Molecular Imaging. DOI: 10.2967/jnumed.120.257808 